\title{
Mental Health Problems among Street Children: the Case of India
}

\author{
DR. TUSHAR SAVARKAR ${ }^{1 *}$ and PROF. SHANKAR DAS ${ }^{2}$ \\ ${ }^{1}$ Independent Researcher. \\ ${ }^{2}$ Mumbai Tata Institute of Social Sciences, V.N. Purav Marg, \\ Eden Gardens, Deonar, Mumbai, Maharashtra, India.
}

\begin{abstract}
A number of studies indicate that street children are vulnerable for exposure to poly-victimization, which includes various types of physical abuse, sexual violence, bullying and exposure to violence, neglect, drug abuse. These children may suffer severe mental health outcomes due to chronic exposure to psychosocial distress, specifically anxiety and depression. An analytical review of the literature was undertaken to examine the research studies on the psychological and social impact of the living condition on the street children from both a national and global lens. Research evidence indicates that there is a strong correlation between mental health and overall holistic development of the individual. The paper finally provides a conceptual framework of vulnerabilities and mental health of street children, implications for future research, interventions and public policy.
\end{abstract}

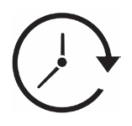

Article History

Received: 21-April 2019 Accepted: 08-July 2019

\section{Keywords}

Mental Health; Psychosocial Distress; Street Children.

\section{Introduction}

Children are the most valuable resource of any society. But early childhood experiences have a profound developmental impact and are established to be a key driver for health and wellbeing in adult life. ${ }^{1}$ Children remain at the lower echelons of the social order and are largely dependent on the adults and their microcosm has a great role to play in molding their personalities. Children are our greatest resource and across the world contribute to almost 33 percent of the world's population. Amongst these, 9 out of 10 children and adolescent population are staying in developing and least developed countries. ${ }^{2}$
India is the second most populous country in the world and four out of ten people are from 0-18 years of age. ${ }^{3}$ However, a large section of the child population is found to be vulnerable and is not able to access their basic rights of livelihood, health, and education. Children living with HIV (CLHA) or children of people living with HIV/ AIDS (PLHA), orphan children, child labor, trafficked child, and the child using an addictive substance, child prone to psycho-social problems and children living / working on street are the most vulnerable group among children. It also noted that the above categories of children are more likely to face mental health

CONTACT Dr. Tushar Savarkar $\$ tusharsavarkar@gmail.com 9 Independent Researcher

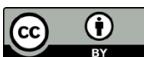

(C) 2019 The Author(s). Published by Enviro Research Publishers.

This is an $\partial$ Open Access article licensed under a Creative Commons license: Attribution 4.0 International (CC-BY).

Doi: http://dx.doi.org/10.12944/CRJSSH.2.1.05 
problems. Studies evidence that homeless, children living or working on street, orphan, abandoned children and children from other marginal section are more prone to mental health issues. ${ }^{4}$

Street children are a majority when it comes to children facing difficult circumstances. Though the accurate figure of street children is hard to quantify, the estimates of the World Health Organization indicate there may be approximately 100 million street children around the world and these children are susceptible to undernourishment, infectious diseases, Sexually Transmitted Diseases (STD) including HIV/AIDS, and criminal and sexual exploitation. ${ }^{5}$ India with a population of 1.21 billion and around four out ten people are from the age group 1-18 years of age group. ${ }^{6}$ Overall, India has over eleven million children who earn their living off the streets in cities and rural areas, ${ }^{7}$ out of which an estimated one million live in metropolitan cities like New Delhi, Kolkata and Mumbai. ${ }^{8}$

Though street children are one of the most vulnerable section of society due to their complex nature and socio-economic, cultural, and political condition, defining this population is difficult. ${ }^{9}$ The UNICEF has categorized children into three major groups, children on the street- having regular contact with their family, children of the street- have very limited contact with their family while abandoned children- not having contact with their family ${ }^{10}$; while the USAID has categorized street children into the four major groups, children staying with street families, children staying in an institutional care, child labour those who work and return to their homes after a specific interval and children who work and or stay on street alone and have no or little contact with their families. ${ }^{11}$ Further, Inter-NGO (cited in UNICEF document) had defined this phenomena as "any girl or boy who has not reached adulthood, for whom the street (in the broadest sense of the word, including unoccupied dwellings, wasteland, etc.) has become her or his habitual abode and /or sources of livelihood, and who is inadequately protected, supervised or directed by responsible adults". ${ }^{2}$ But there are certain problems with the above definition and categorization. The definition has ignored the shifting of one group of children into another group i.e. children of street may become children on street or vice-ver. Also, the definition is to fail to address the process of becoming a street child.

The rapid and unplanned urbanization, migration to the urban areas, the disintegration of the family and community structure leads to the socioeconomic imbalance, such imbalances engenders the phenomena of street children. Street children are virtually uncared-for, staying and working on streets without adult supervision, without love, affection, and care. They are virtually bereft of basic rights like education and health. ${ }^{13} \mathrm{~A}$ study conducted by the Tata Institute of Social Sciences (TISS) and Action Aid in 2013, pointed out that sadly one-fourth of the street children lacked access to even food because of their inability to purchase. ${ }^{14}$ The findings of another study showed that the street children were suffering from various illnesses, fever was the most common among them other being

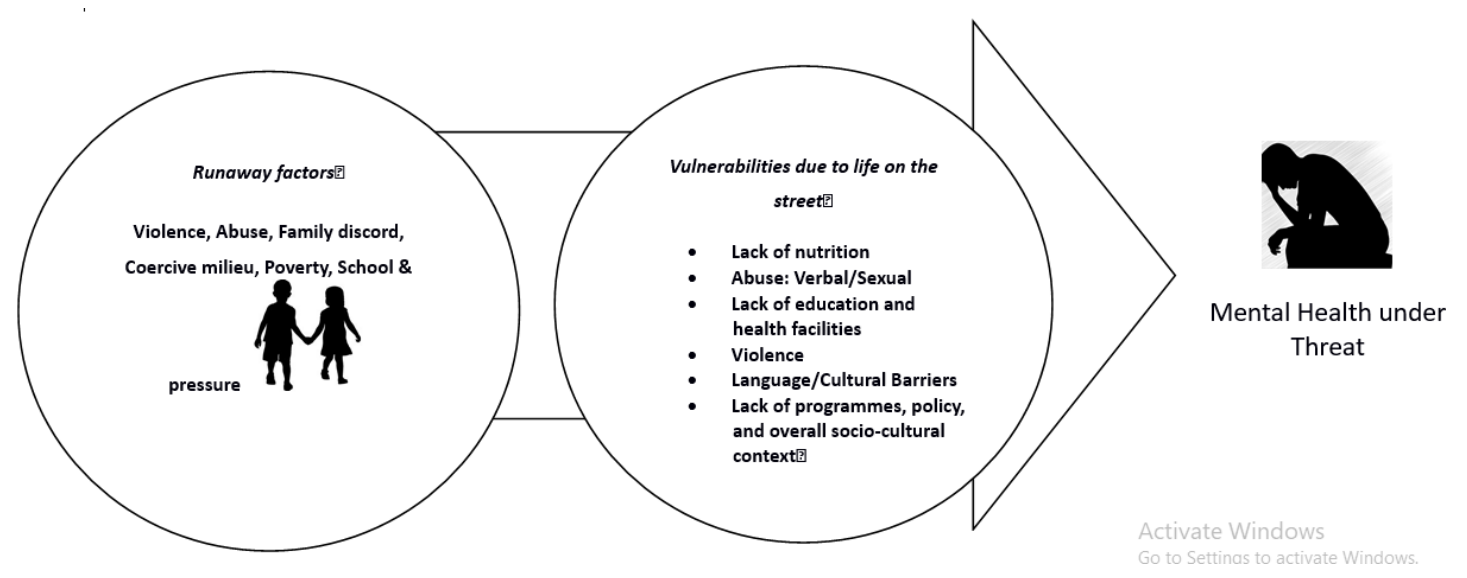

Fig.1: Widening Vulnerabilities Impacting Mental Health of Children on the Streets 
skin infections. ${ }^{13}$ Universally, street children are encounter problems like abuse, torture, violence, exploitation, substance use/abuse and violation of basic rights. ${ }^{15,16}$ Furthermore, earlier research added that homeless children are more vulnerable to accidents, injuries, and burns. ${ }^{17}$ Studies have also shown homeless children who either live or work on streets, orphaned, abandoned, and children from other marginal sections are more prone to mental health issues. ${ }^{4} \mathrm{~A}$ largely unexplored arena of mental health, in general, becomes even more obscure in the case of street children who struggle in almost all areas of health and development. However, this vital component of health needs a deeper understanding of promoting better health standard and framing a policy for children living on the streets.

The article presents an analytical and interpretive review of the mental health of vulnerable children living on the streets. The authors' aim was not simply to produce a scientific text and summary of the evidence on previously published literature; it construes ways that are insightful and useful. The review aimed to investigate and comprehend various psychosocial issues and mental health issues of street children, its determinants and how it affects their overall development. A literature review was undertaken between 1977 and 2018, using the databases like PubMed, Google Scholars, Science direct, Sage, Springer with the help of keywords such as psychosocial distress, street children, and mental health. The inclusion criteria were set at only available full-text of published articles and after identification of relevant articles, those were archived using Endnote. ${ }^{7}$ Initially the titles, abstracts were screened and duplicates were removed electronically with a manual revision, and finally, full-text articles were reviewed.

\section{Prevalence of Mental Health Problems among Children and Adolescents}

Mental health is a growing area of concern, especially amongst vulnerable groups. While it is acknowledged that the mental health problems affect all section of societies and all age groups worldwide; the prevalence rates of psychiatric disorders among children range from 2.6 percent to 35.6 percent. ${ }^{18-21}$ Some studies, however, report that 2 out of 10 young people experience problems related to mental health in any given year. It has also been argued that the age of onset for several chronic mental disorders is age $14 .{ }^{3}$ Another study reported 20 percent of young people to experience some form of mental-health conditions due to various reasons. ${ }^{22}$ An Indian study reported that the prevalence rate of mental and behavioral disorders in India ranged from 9.5 percent to 37 percent in the general population. ${ }^{23}$ A study conducted by Ministry of Health and Family Welfare (MHFW), Government of India (GOI) in 2013 found that while the overall prevalence rate of common mental health disorders is 7 percent, it is 2 percent for severe mental health disorders. Further, it added that around 12 percent of the young population in India is suffering from psychological distress. ${ }^{24}$

Research indicated that the prevalence of depression among young people has risen in recent years. There is a gap in the research on severe depression among the adolescent population in India. The study conducted by Gupta \& Basak in 2013, highlighted the prevalence of depression among adolescents in West Bengal. The study found that around 45 percent of adolescents in the state faced depression, out of these five percent adolescents faced severe type of depression, six percent faced moderate type of depression while 34 percent adolescent faced a mild level of depression. ${ }^{25}$ It has also observed that three out of ten females and 36 percent of males suffer from depression in late childhood. ${ }^{26}$ Another study highlighted that mental illness such as depression, extreme aggression, violent tendencies/behavior, emotional trauma, suicide and substance/drug dependence as common among street children. ${ }^{27}$ The study conducted on homeless children indicated that the lifestyle and hardship of homeless children make them more prone to many mental health issues ${ }^{28}$; about one third of street children showed some signs of pathology in one or more dimensions and one third manifested moderate to severe symptoms of depression, anxiety or acting out. ${ }^{29}$ Likewise, the street children were found suffering from emotional and neurological issues ${ }^{30}$; high level of hopelessness, depression, behavioral problems, and suicidal thoughts ${ }^{31}$; psychosocial distress including depression and anxiety. ${ }^{16}$

The role of circumstances cannot be denied in developing a healthy personality. The struggle for existence on the streets is complicated by a variety of factors to which these children get exposed to 
regularly. This leads to psychological distress which remains unidentified and unaddressed causing damage to the mental health of these children.

\section{Determinants of Mental Distress}

The assessment of mental health disorders requires a multi-dimensional framework in that several risk factors attenuate or increase the likelihood of developing socio-emotional challenges..$^{32}$ Factors like poverty, rejection, isolation, violence, lack of moral support are alarming for the mental health condition of the individual. ${ }^{33}$ In addition to these, limited educational opportunity, stigma, sexual, physical and emotional abuse, and inadequate health care are the main reasons of mental health problems among young people but children are more likely to be afflicted than adults. ${ }^{34}$ Children are largely dependent on the adults for their holistic wellbeing as they need love and support throughout their developmental cycle. Life on the streets jeopardizes their access to basic needs, hence makes them more vulnerable. The findings of an earlier study indicated the hardship of homelessness leads to long-term mental illness among the children. ${ }^{28}$ The inevitable exposure to poverty, physical, emotional, verbal and sexual abuse, inadequate or no health care, substance use, and violence has tremendous potential to push them to experience distress, anxiety leading to behavioral problems. ${ }^{35,36}$ The previous research which addressed the psychosocial distress among the children living on the street found that age, time spent on the street, type of work are the main determinants of the psychosocial distress among these children. ${ }^{16}$

The importance of family in the lives of children is well established in all cultures. Familial relationships are nurturing and enriching and help in the overall development of the child. But the street children largely consist of the group of runaway children, children left by parents or relatives, and the children those who are staying with homeless parents. In all these situations they have no or very little family contacts and has poor social relationships. Many a time the cause for their expulsion/withdrawal from family is rooted in deeper social problems like extreme poverty, violence, abuse which may result in mental health depreciation. The lifestyle and working conditions bring street children closer to many forms of substances and for quick relief of stress and experience of elation they sniff whitener and glue that helped them work longer. ${ }^{14}$ The researchers indicated that there is a strong relationship between substance abuse and the distress among the street children. Substance abuse further gives rise to the risk of other health problems, which includes risky sexual behavior, HIV, STD, physical illness and distress. ${ }^{37}$

Some studies reported children to face domestic violence and physical punishment in many societies; physical punishment is a very common tool and reckoned as an effective means to discipline the children. But studies have shown that it has the negative impact on the development of children and those who were subjected to physical punishment have more probability to be involved in violent behavior, aggression, poor quality of social relationships and increased delinquent behavior ${ }^{38}$ and sexual abuse. ${ }^{27}$ Further, it was reported, those children who suffered the sexual exploitation or trafficking had faced severe mental health problems like trauma, post-traumatic stress disorder and other psychological distress. ${ }^{38}$ There is a close relationship between sexual harassment and mental health problems. The findings reveal that street children those who exposed to harassment and sexual violence are more likely to face hopelessness. ${ }^{39}$ The place of residence is an important determinant of mental health. The prevalence of mental health issues in urban areas was double than in rural areas. Along with all these micro factors, the socio-economic and political environment of the country also played an important role in the overall development of the children. Thus, this necessitates a greater need to research mental health and psychosocial distress in local social-cultural perspectives rather than from a universal perspective..$^{40}$

The economic level of the country determines the health and mental health scenario of the country. Studies indicated regional and socio-cultural variations that affect the mental health of the children. Health and mental health of children and adolescents are affected by the nutrition and quality of food that they consume that finally determine their immunity, growth, and health. Weinreb highlighted the correlation between food or nutrition with the health and mental health of individuals. It was also found that hunger affects the mental health of the 
individual negatively. ${ }^{41}$ Street children are surviving without proper shelter and besides they don't have the regular provision of food. Some of them procure food at public or religious places distributed by the benevolent people and others manage with meager money earned through miscellaneous job or work in exchange for food. The findings of TISS and Action Aid revealed that one-fourth of the children on the street situations was not able to access their daily and sufficient food because of their inability to purchase due to hardship and lack of livelihood means on the street. Though a large section of them managed food through different means whatever food they could manage to access the quality was neither good nor healthy. ${ }^{14} \mathrm{~A}$ few studies also reported evidence of prevalent physical illnesses such as fever, upset stomach, skin infections. ${ }^{42}$ Physical well being is an important determinant of mental health. Physical illness leads to distress and other mental health problems. ${ }^{43}$

Figure 1 attempt to summarize the vulnerabilities in the environment for children who land up on streets and subsequently may fall prey in developing some sort of mental health problems and disorders. The vulnerability leads to mental health problems and in a similar way mental health problems push people towards a vulnerable situation. Similarly, people suffering from poverty are more likely to face malnutrition, poor health, distress, exclusion, neglect and so on. All such factors contribute to mental health problems. In the same manner, street children are living in poverty, facing social exclusion and human rights violation. All these eventuate in the poor health and mental health of street children. Street children go through the hardships of street life and suppression of the aspirations resulting in identity crises, distress, and being outcast from the mainstream of society. ${ }^{44}$ Mental illness is not an independent phenomenon. It is a result of multiple factors like biological, psychological and social factors. In the case of socioeconomic issues like urbanization, poverty, technological changes- all these factors impact the mental health of an individual. Though the above factors are correlated with the mental health, mental and behavioral disorder but the impact are not similar for every individual of the community. ${ }^{45}$ Adversely, the children who were found with symptoms of depression have a history of suicidal thoughts, suicidal planning and attempt to suicide and so on. ${ }^{31}$

The lifestyle of street children makes them prone to many kinds of abuse, neglect, stigmatization, illtreatment, torture, and harassment by the people and police. All these factors lead to exacerbation of the mental health problems among the street children. On the other hand, poor mental health condition and mental illness further make them more vulnerable; the cyclic relationship between vulnerability and poor mental health are given in their life.

\section{Mental Health Problems}

Research evidence indicates that there is a strong correlation between mental health and overall holistic development of the individual. Good quality of life is often considered as the foundation of sound mental health and the adolescents those who are bestowed with opportunities may grow up to be happy adults ${ }^{46}$ and during the later parts of life, it affects their social and economic lives. ${ }^{4}$ Mental health conditions are the leading causes of health problems among children and youth across the world. ${ }^{47}$ Depression in children and adolescent harms their overall development. Depression among young people is rapidly proliferating across the world and this is a major reason for suicide among young people. .,31,35 $^{3}$ A study reported that there was a strong relationship between mental health problems and the prediction of the psychiatric condition in street children. It further illustrated that mental health problems and levels of stress co-exists. ${ }^{48}$

Mental health problems affect the social as well economic life of the street children and further, it leads to the poverty, fewer employment opportunities, poor work efficiency. ${ }^{49}$ Given the fact mental illness leads to the vulnerability of individual and also since street children are those who left the home due to the maladjustment in the family, this eventuates in psychological distress among them. Once they reach the street they suffer stigma, discrimination, and abuse which worsen their condition. Hence, they are more likely to suffer mental distress and behavioral problems. In connection with the above study, street children suffer from problems like abuse, neglect violence and other forms of vulnerabilities; these lead to the mental health problems among street children. 
Again these mental illnesses make them more vulnerable and push them on the margin of social exclusion and violation of many rights. As the street children go through the numerous hardship of street life that undoubtedly leads to many psycho-social distresses and mental health problems among them.

However, positive qualities of resilience, protective resources among street children are reported by a researcher which often goes unnoticed. Their findings changed the popular perception of street youth as vulnerable; on the other hand, depicted a picture of young youths with potential for negotiation, resilient trajectory, personal resources (that are typically unconventional), bonds to their peer groups, and religiosity, to cope resiliently with the multiple challenges of street life. ${ }^{50}$

\section{Conclusion}

It is important to recognize the variability of experiences among children living on the street, not all street children experience a comparatively higher level of negative life circumstances than their previous living situations. The present paper highlights the various problems of street children, the prevalence of the mental health issues, its determinants and impact of mental health issues on their overall development. Most studies highlighted the street children population is marginalized and vulnerable where they live and work without proper adult supervision. All these factors affect the quality of life, healthy socialization, overall development and mental health of the street children. Given the limited amount of research in this area, inconsistent outcome measures and imperfect study designs maintain that this is an area in need of greater attention and research focus.

\section{Aknowledgement \\ Nil \\ Conflict of Interest \\ Nil}

\section{References}

1. Centers for Disease Control and Prevention (CDC). (2019). Adverse Childhood Experiences (ACEs). Retrieved June 28, 2019, from

ttps://www.cdc.gov/violenceprevention/ childabuseandneglect/acestudy/index.html

2. United Nations Children's Fund (UNICEF) 2008). Statistics and Monitoring. New York: UNICEF. Retrieved Jan 10, 2019, from https://www.unicef.org/publications/index_ pubs_2008.html.

3. United Nations Children's Fund (UNICEF) (2011). Adolescent mental health: An urgent challenge for investigation and investment, The State of World's Children 2011. New York: UNICEF.

4. United Nations (2013). Social Inclusion of Youth with Mental Health Conditions. New York: UNITED NATION.

5. World Health Organization (WHO) (2017). Depression in India: Let's talk. Retrieved Jan 10, 2019, from http://www.searo.who.int/india/ depression_in_india.pdf.
6. Nayar, U., \& Das, S. (2012). Mental Health of Children and Adolescent in Contemporary India. In U. Nayar, Child and Adolescent Mental Health (pp. 337-350). New Delhi: SAGE Publication Pvt Ltd.

7. Verma, S., \& Saraswathi, T. (2002). Adolescence in India: Street Urchins or Silicon Valley Millionaires? In B. Bradford Brown, R. Larson, \& T. Saraswathi (Eds.), The World's Youth: Adolescence in Eight Regions of the Globe (pp. 105-140). Cambridge: Cambridge University Press. doi:10.1017/ CBO9780511613814.005.

8. Naik R., Bansode S., Shinde R., Nirgude A. (2011). Street children of Mumbai: demographic profile and substance abuse. Biomedical Research. 22 (4): 495-498. Retrieved Jan 10, 2019, from http://www. biomedres.info/biomedical-research/streetchildren-of-mumbai-demographic-profileand-substance-abuse.pdf

9. Lusk, M. W. (1989). "Street Children Programs in Latin America," The Journal of Sociology 
\& Social Welfare: Vol. 16: Iss. 1, Article 6. Retrived March 08,2018 from https:// scholarworks.wmich.edu/jssw/vol16/iss $1 / 6$.

10. UNICEF. (1988). Background paper prepared by UNICEF. The National Workshop on Street Children. New Delhi: Ministry of Welfare, Government of India.

11. Bhaskaran, R., \& Mehta, B. (2011). Surviving the Streets: A census of street children in Delhi. New Delhi: IHD and Save the Children.

12. UNICEF (2001) A Study on Street Children in Zimbabwe Retrieved from Retrived Feb 12,2019from https://www.unicef.org/ evaldatabase/files/ZIM_01-805.pdf.

13. D'Lima, H., \& Gosalia, R. (1992). Street Children of Bombay: A situational analysis. Noida: National Labor Institute.

14. Tatalnstitute of Social Sciences \& Action Aid. (2013). Making Street Children Matter: A Census Study in Mumbai. Mumbai: TISS Action Aid.

15. Dabir Neela and Athale Naina (2011): From street to hope; faith-based and secular programs in Los Angeles, Mumbai, and Nairobi for Street Living Children, Sage Publication India Pvt Ltd, New Delhi.

16. Savarkar T (2018) Psychosocial Distress among Children Living on the Street in Mumbai City, India. J Depress Anxiety 7: 308. doi:10.4172/2167- 1044.1000308.

17. Vostanis Panos (2001): Mental Health of Homeless children and their families, Advances in Psychiatric treatment (2002), vol. 8, pp.463-469.

18. Anita, Gaur, D. R., Vohra, A. K., Subash, S., \& Khurana, H. (2003). Prevalence of psychiatric morbidity among 6 to 14 years old children. Indian Journal of Community Medicine, 28(3), 133-137.

19. Hackett, R., Hackett, L., Bhakta, P., \& Gowers, S. (1999). The prevalence and association of psychiatric disorders in children in Kerala, South India. Journal of Child Psychology and Psychiatry, 40(5), 801-807. doi:10.1111/1469-7610.00495

20. Deivasigamani, T. R. (1990). Psychiatric morbidity in primary school children: An epidemiological study. Indian Journal of Psychiatry, 32(3), 235-240.
21. Lal, N., \& Sethi, B. B. (1977). Estimate of mental ill health in children of an urban community. Indian Journal of Paediatrics, 44(3), 55-64.

22. Kessler, R., Berglund, P., Demler, O., Jin, R., \& Walter, E. (2005). Lifetime prevalence and age-of-onset distributions of DSM-IV disorders in the National Comorbidity Survey Replication. Chicago: Archive of General Psychiatry.

23. Math, S. B., Chandrashekar, C. R., \& Bhugra, D. (2007). Psychiatric epidemiology in India. Indian Journal of Medical Research, 183-192.

24. MHFW. (2013). Annual Report 2012-13. New Delhi: Ministry of Health and Family Welfare.

25. Gupta, S., \& Basak, P. (2013). Depression and type $D$ personality among undergraduate medical students. Indian Journal of Psychiatry,55 (3), 287-289.

26. Sidhu, R., \& Singh, G. (2012). Prevalence of depression in late childhood, Indian Journal of Psychology and Mental Health,6(1), 90-97.

27. Dabir, N. (2005). Rebuilding Lives of Street Children; A Study of Street Children's Organisations in Mumbai and Role of Faith and Religion in Service Delivery. Mumbai: Department of Family and Child Welfare, TISS.

28. Vostanis P., Grattan E. and Cumella S. (1998): Mental Health Problems of Homeless Children and families: a longitudinal study, BMJ1998;316:899-902.

29. Richter, Linda. Van der Walt, Michelle, "The Psychological Assesment of South African Street Children". Children, Youth and Environment 13(1), Spring 2003.

30. Aptekar Lewis (1988): Colombian Street Children: Their mental Health and How they can be Served, International Journal of Mental Health, vol. 17, no. 3, pp. 81-104.

31. Khurana S., Sharma N., Jena S., Saha R. and Ingle G. K. (2004): Mental Health Status of Runaway Adolescents, Indian Journal of Pediatrics, vol. 71- May 2004, pp; 405-409.

32. Morgan, A., Currie, C., Due, P., Gabhain, S., Rasmussen, M., Samdal, O., et al., (2008). Mental we-being in school-aged children in Europe: associations with social cohesion and socioeconomic circumstances. In WHO, 
Social cohesion for mental well-being among adolescents (pp. 12-25). Copenhagen:WHO.

33. WHO, (2004). Prevention of mental disorders: effective interventions and policy options: summary report. Geneva: WHO.

34. Das S., Das A. \& Leibowitz, G. (2012). Impact of HIV/ AIDS on Mental Health of Children and Adolescents in India. In U. Nayar, Child and Adolescent Mental Health (pp. 57-74). New Delhi: SAGE Publication, Pvt Ltd.

35. WHO, (2003). Caring for children and adolescents with mental disorders: setting WHO directions. Geneva: WHO.

36. Pattnayak, R., \& Mehata, M. (2012). Childhood and Adolescent Depression. In U. Nayar, Child, and Adolescent Mental Health. New Delhi: SAGE Publication, Pvt Ltd.

37. Embleton, L., Mwangi, A., Veerman, R., Ayuku, D., \& Braitstein, P. (2013). The epidemiology of substance use among street children in resource-constrained settings: a systematic review and meta-analysis. Addiction, Vol. 108, 10, 1697-1869.

38. World Vision. (2012). Fact sheet: Child labor Effects on the child. Melbourne: WorldVision.

39. Duyen, V. (2005). Duyen, V. (2005): Relationships between the Socio-demographic and Family Characteristics, Streetlife experiences and the hopelessness of street children. ,. London. Childhood, Vol. 12 (4), 445- 459.

40. Reddy, V. M., \& Chandrashekar, C. R. (1998). Prevalence of mental and behavioral disorders in India: a meta-analysis. Indian J Psychiatry, 40(2):149-57.

41. Weinreb, L, (2002). Hunger: Its Impact on
Children's Health and Mental Health. Vol. 110 No. 4, 1: PEDIATRICS.

42. SNEHA. (2008). Making Health Care Accessible to Street Children: The 'Hospital on Wheels' Project (2000- 2006). Mumbai: SNEHA.

43. Johnson, B., \& Francis, J. (2005). Emotional and Behavioural Problems in Children and Adolescents with Congenital Heart Disease. JIACAM, Vol. 1, No. 4, Article 5.

44. West, A, (2003). At the margins: Street children in Asia and the Pacific. Manila: Asian Development Bank.

45. WHO, (2001). The World health report on Mental health: new understanding, new hope. Geneva: WHO.

46. Rao, M. (2001). Promoting children's emotional well-being: a book review. Journal of Public Health Medicine, 23, 2, 168.

47. WHO, (2008). Mental health policy development and implementation in South Africa: a situation analysis. Geneva: WHO.

48. Imasiku Mwiya L. and Serah Banda (2015). Mental health problems of street children in residential care in Zambia: Special focus on the prediction of psychiatric conditions in street children. Journal of clinal Medicine and research, Vol. 7 (1), PP1-6, March 2015.,

49. Kessler, R., \& Frank, R. (1997). The impact of psychiatric disorders on work loss days. Psychological Medicine, 27(4), 861-873.

50. Macalane J. Malindi and Linda C. Theron (2010). The hidden resilience of street youth, South African Journal of Psychology, Volume 40 , Issue 3, Sep 2010, p. 318 - 326. 